INDO GLOBAL JOURNAL OF

PHARMACEUTICAL SCIENCES

ISSN 2249- 1023

\title{
Biodegradation of Pesticide Phorate Employing Native Rhizobacterial Isolates
}

\author{
Pratibha Yadav, S. Krishna Sundari * \\ Jaypee Institute of Information Technology (JIIT), A-10, Sector-62, Noida, 201309, U.P., India \\ Address for Correspondance: S. Krishna Sundari, krishna.sundari@jjiit.ac.in ; skrishnasundari@gmail.com
}

Keywords Phorate

Residue;

Biodegradation;

Fourier

Transformation

Infrared

Spectrophotometer;

Catabolism.

\begin{abstract}
Phorate is a highly toxic organophosphate pesticide extensively applied in India to control crop pests like beetles, borers, leaf worms etc. The theoretical maximum daily intake (TMDI) of phorate for adults is $0.0564 \mathrm{mg} / \mathrm{day} / \mathrm{kg}$ body weight while the acceptable daily intake (ADI) is $0.042 \mathrm{mg} / \mathrm{day} / \mathrm{kg}$ body weight. This brings about the concern on unintentional or accidental intake of phorate and its devastating effects on animal and human health. Very few reports are available on phorate biodegradation that too in concentration ranges $20-300 \mathrm{mg} / \mathrm{lit}$. Hence it is imperative that more research has to be undertaken to target degradation of higher concentration of this pesticide using biologically safe microorganisms. The current study attempts to provide a bioremediation solution to degrade persistent phorate residues in the environment. Our initial emphasis was on testing select native rhizobacterial isolates (RB1, RB2, RB3 and RB4) with maximum tolerance limits represented as MIC and LD50 towards phorate. The study reports highest tolerance of all our isolates towards phorate with MIC values ranging between $1600-1850 \mathrm{mg} /$ lit making it the first report till date. Further, phorate catabolism by isolates was studied using phorate exclusively as carbon or phosphate source. The carbon and phosphate exclusion studies confirms that phorate is been utilized by RB1, RB2 and RB3 isolates preferentially as phosphorous source where as RB4 preferably utilize phorate as sole carbon source. Subsequently the breakdown intermediates and end products was analysed using Fourier transformation infrared spectrophotometer (FTIR). Findings of FTIR analysis further supported our results showing shift in FTIR peak of microbe treated samples along with reduction in their peak intensity as comparison to parent (pure) compound. Rhizobacteria treated samples also showed disappearance of specific band's (1025.43, 998.37 and $908.99 \mathrm{~cm}^{-1}$ ) reflecting ester linkages prominently observed in parent compound. Thus we conclude that rhizobacterial isolates RB1, RB2, RB3 and RB4 provide a competitive option to degrade phorate residues while with standing higher initial concentrations persistent phorate residues.

(C) 2016 iGlobal Research and Publishing Foundation. All rights reserved.
\end{abstract}

Conference Proceedings: International Conference on Advances in Plant and Microbial Biotechnology (PMB2017); JIIT, Noida: February 02-04, 2017

Indo Global Journal of Pharmaceutical Sciences( ISSN 22491023 ; CODEN- IGJPAI; NLM ID: 101610675) indexed and abstracted in EMBASE(Elsevier), SCIRUS(Elsevier),CABI, CAB Abstracts, Chemical Abstract Services(CAS), American Chemical Society(ACS), Index Copernicus, EBSCO, DOAJ, Google Scholar and many more. For further details, visit http://iglobaljournal.com 